\title{
A Comparative Study between Two Central Venous Access Techniques Performed by Junior Residents
}

\author{
Alberto Ferraz de Melo-Neto, Dyego Espírito Santo de Oliveira, Oldack da Silva Miranda-Neto, Guilhermanda \\ Nicéias Tenório de Brito Sobral, Thales Paulo Batista*, Antônio Cavalcanti de Albuquerque Martins and \\ Cristiano de Souza Leão \\ Department of Surgery/Oncology, FPS/IMIP - Faculdade Pernambucana de Saúde, Instituto de Medicina Integral \\ professor Fernando Figueira, Rua dos Coelhos, 300 - Boa Vista-CEP: 50070-550; Recife/PE, Brazil
}

Received:September 26, 2014; Accepted: March 02, 2015, Published: March 15, 2015

*Corresponding author: Thales Paulo Batista, Department of Surgery/Oncology, Rua Pio IX, 435, Ap; 701/B, 50710-260, Recife/PE, Brazil, Tel: +5581-8886-12-03; E-mail: t.paulo@bol.com.br

\begin{abstract}
Objective: To evaluate the outcomes of Central Venous Access (CVAs) performed by junior residents (i.e. first-year residents) using the Subclavian (SC) and Internal Jugular (IJ) approaches.

Methods: A comparative study was carried out in a prospective cohort of patients who consecutively underwent SC or IJ CVAs performed by junior residents at our Department of General Surgery. Additionally, we examined the impact of learning curve on the success of the venipunctures. Statistical analyses were developed using conventional nonparametric methods.
\end{abstract}

Results: Overall, success and morbidity rates in our sample were $81 \%$ and $18 \%$, respectively. Successful rates did not significantly differ between IJ and SC approaches (80.35\% and $81.81 \%$, respectively; $p$ $=0.942$ ), among procedures performed from first to fourth quartile periods $(72 \%$ vs. $80 \%$ vs. $80 \%$ vs. $92 \%$, respectively; $p=0.854$ ) or regardless of which junior residents performed it $(p=0.662)$. Similarly, morbidity rates did not differ significantly according to CVA techniques ( $17.85 \%$ vs. $18.18 \% ; p=0.825)$, quartile periods $(28 \%$ vs. $16 \%$ vs. $20 \%$ vs. $8 \%$; $p=0.832$ ), or which junior residents performed it $(p=0.743)$. There were significantly more arterial punctures/ hematoma using the IJ approach ( $7 \%$ vs. $1 \%, p=0.024)$ and catheter malpositions/nonprogression after the SC technique ( $1 \%$ vs. $6 \%, p=$ 0.012).

Conclusions: There was a different profile of complication rates with no differences between the techniques in term of either successful or early morbidity. Our study suggests that both approaches may be used for surgical training of junior residents in general surgery.

Keywords: Central venous catheterization; Medical education; Surgical procedures

\section{Introduction}

Central Venous Access (CVA) is a common procedure in the management of various medical conditions, providing rapid access for fluid and blood administration, hemodynamic monitoring, pacemaker insertion, and maintenance of durable access for parenteral nutrition. This procedure is often taught in residency training programs, and competency in this skill is a stated objective for many training programs in general surgery and subspecialties $[1,2]$.

The standard landmark-guided Subclavian (SC) and Internal Jugular (IJ) approaches are common bedside procedures for CVAs performed by junior residents (i.e. first-year resident) in general surgery. Despite both techniques appears similar in terms of either successful or complication rates $[3,4]$, there are no clear evidence if any of these approaches is better to be taught initially during the early learning curve of training in surgical procedures. Therefore, this current study aimed to evaluate these two different CVAs performed by junior residents, since an estimation of the outcomes might help guide medical educators in terms of where to focus their curriculum efforts.

\section{Materials and Methods}

A comparative study was carried out in a prospective cohort of patients treated at the IMIP - Instituto de Medicina Integral Professor Fernando Figueira, a tertiary-care general hospital in Recife, Brazil. Empirically, we selected the first 100 patients that consecutively underwent the most common CVA performed at our center, the SC and the IJ approaches. Our study was also limited to adult patients ( $\geq 18$ years) with some oncological diagnosis who underwent temporary CVA by indication according to their medical assistant team judgment.

Applying the Seldinger method [5], all procedures were performed at the bedside by our junior residents (i.e., first-year residents) under the supervision of our staff surgeons, using the standard landmark-guided infraclavicular and anterior techniques for SC [6] and IJ [7] approaches, respectively. No recommendation for side choosing was provided, but the residents were instructed to perform both techniques, alternately, unless a specific contraindication was present. Ultrasound was not available for any of the CVA techniques. After the procedure, a chest $x$-ray was obtained immediately to confirm the appropriate placement and to assess for complications.

Successful procedures were defined as those where morbidity 
was absent, and venipuncture was effective in a maximum of three needle passes. Morbidity was assessed using the early mechanical complications observed in the first 24 hours after puncture such as hematoma, arterial punctures, catheter non progression or malposition, and hemothorax or pneumothorax. To study the learning curve, we divided the procedures successively performed into quartile periods, which is similar to a method we had previously applied in previous studies [8,9].

Descriptive statistics, rates of successful and morbidity were summarized as medians (interquartile range) or frequencies (percentages) and analyzed using conventional statistical methods, considering a two-tailed $p$-value of 0.05 as statistically significant. This study was approved by our ethics research committee (protocol number 2875) and partially presented as a poster (PO 1268) during the XXX Brazilian Congress of Surgery.

\section{Results}

One hundred-three consecutive patients undergoing CVA performed by our four junior residents from February 2011 to February 2012 were initially selected for analysis. However, three of them were excluded because of inappropriate records $(n=1)$ and puncture after the sample size required was accomplished $(\mathrm{n}=2)$. Among the patients analyzed, $35 \%$ had previous history of central venous assessment in the past, whereas the most part of CVA procedures in this current study were performed by the right side (88\%). Fifty-six patients (56\%) underwent venipunctures using the IJ approach and 44 (44\%) using the SC technique. Their baseline characteristics and descriptive

Table 1: Baseline characteristics and descriptive statistics according to patients- and procedures-related variables.

\begin{tabular}{|c|c|c|c|c|}
\hline \multirow[b]{2}{*}{ Variable } & \multicolumn{4}{|c|}{ Venipuncture Approach ${ }^{1}$} \\
\hline & Overall $^{1}$ & Internal Jugular Vein & Subclavian Vein & p-value ${ }^{2}$ \\
\hline \multicolumn{4}{|l|}{ Quartile Period } & 0.995 \\
\hline First $(2.6 .11-6.15 .11)$ & $25(25)$ & $12(21.42)$ & $13(29.54)$ & \\
\hline Second (6.16.11-8.16.11) & $25(25)$ & $14(25)$ & $11(25)$ & \\
\hline Third (8.17.11-10.17.11) & $25(25)$ & $15(26.78)$ & $10(22.72)$ & \\
\hline Fourth (10.18.11-2.18.12) & $25(25)$ & $34(26.76)$ & $10(22.72)$ & \\
\hline \multicolumn{4}{|l|}{ Side } & 0.449 \\
\hline Right & $88(88)$ & $51(91.1)$ & $37(84.1)$ & \\
\hline Left & $12(12)$ & $5(8.9)$ & $7(15.9)$ & \\
\hline \multicolumn{4}{|l|}{ Needle Passes } & 0.859 \\
\hline One & $65(65)$ & $38(67.85)$ & $27(61.36)$ & \\
\hline Two & $19(19)$ & $8(14.28)$ & $11(25)$ & \\
\hline Three $^{3}$ & $16(16)$ & $10(17.85)$ & $6(13.63)$ & \\
\hline \multicolumn{4}{|l|}{ Diagnosis (Oncological) } & 0.743 \\
\hline Upper GI & $32(32)$ & $22(39.28)$ & $10(22.72)$ & \\
\hline Hematological Cancers & $28(28)$ & $15(26.78)$ & $13(29.54)$ & \\
\hline Coloproctology & $14(194)$ & $9(16.07)$ & $5(11.36)$ & \\
\hline Breast and Gynecology & $9(9)$ & $3(5.35)$ & $6(13.63)$ & \\
\hline Others $^{4}$ & 17 (17) & $7(12.5)$ & $10(22.72)$ & \\
\hline \multicolumn{4}{|l|}{ Indication } & 0.717 \\
\hline Chemotherapy & $78(78)$ & $47(83.92)$ & $31(70.45)$ & \\
\hline Fluids Infusion and Monitoring ${ }^{5}$ & $16(16)$ & $6(10.71)$ & $10(22.72)$ & \\
\hline Parenteral Nutrition & $6(6)$ & $3(5.35)$ & $3(6.81)$ & \\
\hline INR & $1.1(1.02-1.2)$ & $1.09(1.01-1.18)$ & $1.1(1.03-1.27)$ & 0.194 \\
\hline Platelet Count $\left(\times \mathbf{1 0}^{3}\right)$ & $263(183.5-325.5)$ & $239.5(187.5-311.5)$ & $297(165-447)$ & 0.194 \\
\hline Age (years) & $51(35-60)$ & $49.5(34-56.5)$ & $53.5(36-70)$ & 0.077 \\
\hline Gender & & & & 0.52 \\
\hline Male & $57(57)$ & $34(60.71)$ & $23(52.27)$ & \\
\hline Female & $43(43)$ & $22(39.29)$ & $21(47.73)$ & \\
\hline \multicolumn{4}{|l|}{ Venipuncture History } & 0.999 \\
\hline Same Approach & $22(22)$ & $13(23.21)$ & $9(20.45)$ & \\
\hline Same Side & $28(28)$ & $16(28.57)$ & $12(27.27)$ & \\
\hline Both & $15(15)$ & $9(16.07)$ & $6(13.63)$ & \\
\hline
\end{tabular}

Summarized as medians (interquartile range) or frequencies (percentages), as appropriated.

${ }^{2}$ Mann-Whitney U-test or chi-square tests, including Yates's correction and Fischer's exact test as appropriated.

${ }^{3}$ Including one case with 4 needle passes and other with 5 needle passes.

${ }^{4}$ Hepatobiliopancreatic $=5$; head and neck=4; thorax $=3$; urology $=2$; others $=3$.

${ }^{5}$ Including one case for invasive monitoring and one case because of catheter-related infection (exchange of the catheter). 
statistics according to patient's variables and procedure-related variables are summarized in Table 1.

Overall, success and morbidity rates in our sample were $81 \%$ and $18 \%$, respectively. Success rates did not significantly differ between IJ and SC approaches $(80.35 \%$ and $81.81 \%$, respectively; $p=0.942$ ). Also, there were no statistical difference in this rate among procedures performed from first to fourth quartile periods $(72 \%$ vs. $80 \%$ vs. $80 \%$ vs. $92 \%$, respectively; $p=0.854)$ or regardless of which junior residents performed it ( $p=0.662)$. Similarly, morbidity rates did not differ significantly according to CVA techniques $(17.85 \%$ vs. $18.18 \% ; p=0.825)$, quartile periods (28\% vs. $16 \%$ vs. $20 \%$ vs. $8 \%$; $p=0.832)$, or which junior residents performed it ( $p=0.743$ ). We also confirmed no statistical difference in success or morbidity rates between the first and fourth quartiles (72\% vs. $92 \%, p=0.138$, and $28 \%$ vs. $8 \%, p=0.138$; respectively).

Table 2 summarizes the complication rates in our sample. Accordingly, there were significantly more arterial punctures/ hematoma using the IJ approach (7\% vs. $1 \%, p=0.024)$ and catheter malpositions/non progression after the SC technique ( $1 \%$ vs. $6 \%, p=0.012$ ).

\section{Discussion}

The Brazilian National Ministry of Education officially implemented the medical residency programs as postgraduate specialization courses for medical doctors in the 1970s, but they were previously used as a training model since the 1940s $[10,11]$. Currently, these programs are the main method to train specialist physicians in our country after a regular medical course lasting six years. In the general surgery field, a core curriculum guided by medical and surgical competencies has been normalized by our National Committee of Medical Residency (CNRM) since 2006 [12]. In these settings, our medical residency program has offered four new openings a year for the surgical training program in general surgery, which has been mostly preferred by medical doctors interested in this medical field at our state (Pernambuco).

Table 2: Frequency of puncture complications after the central venous access procedures.

\begin{tabular}{|l|c|c|c|c|}
\hline \multicolumn{5}{|c|}{ Venipunctures Approach (n) } \\
\hline Morbidity & $\begin{array}{c}\text { Overall } \\
\text { (n) }\end{array}$ & $\begin{array}{c}\text { Internal Jugu- } \\
\text { lar Vein }\end{array}$ & $\begin{array}{c}\text { Subcla- } \\
\text { vian Vein }\end{array}$ & $\begin{array}{c}\text { p-val- } \\
\text { ue }^{1}\end{array}$ \\
\hline $\begin{array}{l}\text { Arterial Punctures or } \\
\text { Hematoma }\end{array}$ & 8 & 7 & 1 & 0.024 \\
\hline $\begin{array}{l}\text { Catheter Malposition or } \\
\text { Non progression }\end{array}$ & 7 & 1 & 6 & 0.012 \\
\hline $\begin{array}{l}\text { Non puncture (vein not } \\
\text { found) }\end{array}$ & 2 & 2 & - & 0.477 \\
\hline Pneumothorax & 1 & - & 1 & 0.444 \\
\hline
\end{tabular}

${ }^{1}$ Appling the Fischer's exact test and considering only the total complicated cases.

${ }^{2}$ Hematoma in 2 cases. One of them after an arterial puncture and other case without arterial puncture (venous hematoma).

${ }^{3}$ Non progression in 4 cases and malposition in 3 cases.
The ability to perform CVA competently is an important part of the initial surgical training [13], and both standard techniques of SC (infraclavicular approach) and IJ (anterior approach) access procedures have been mainly and equally taught at our department in order to provide our residents with comprehensive surgical skills in performing CVA. From an anatomical point of view, right-sided procedures have been preferred [14], and other alternative techniques of CVA by puncture or surgical cut-down access has also been taught. Thus, exploring some evidence to select the best approach to teach initially during the early learning curve of the surgical training, we examined a cohort of patients who consecutively underwent CVA performed by junior residents from our department. Herein, the overall rates of successful CVA and morbidity did not significantly differ between the techniques and were found to be similar to those from other recent studies [3,4,15-18], but interestingly, we found no significant impact by the resident learning curve on these outcomes. Because of an absolute statistically nonsignificant difference of $20 \%$ between rates from the first to the last quartile periods, we supposed these findings mainly resulted from our limited sample size, since this difference is probably important from a clinical point of view. Similarly, we also observed there are more arterial punctures but less catheter malpositions with the internal jugular compared with the subclavian access, as previous reported by Ruesch S et al. [3] in a systematic review including data on 2,085 jugular and 2,428 subclavian catheterizations from 17 prospective comparative trials.

Many studies have confirmed that both landmark-guided CVA techniques are feasible and safe with similar complication rates $[3,4,15]$, but the ultrasound-guided techniques have showed lower proportion of failures and complications rates $[19,20]$. Ultrasound-guided CVA is a helpful technique to gain CVAs [21] and the learning process of ultrasound-guided CVAs appears safe and feasible for training medical residents [16]. Although the ultrasound-guided techniques already has been incorporated into our currently developing medical residency program in general surgery, unfortunately, ultrasound devices had not been easily available for our residents at the time of this study.

Despite a relatively small sample size, the main scientific merit of this study was to explore this issue in the context of surgical training, whereas an estimation of success and morbidity rates might help guide our medical educators in terms of teaching bedside procedures and also be used as baseline for planning future clinical trials. Furthermore, our database had been prospectively collected and continuously updated to our own feedback, while the residents were instructed to perform both techniques alternately unless a specific contraindication was present. These approaches played a role as a simplified method of randomization in this analysis. Finally, to add some homogeneity to our sample, we limited this study to adult patients with a cancer diagnosis, because it was previously observed that most CVAs have been performed in this setting at our department.

\section{Conclusions}

We only observed a different profile of complication rates with no others differences between the IJ and SC approaches in 
term of either successful or early morbidity. Our study suggests that both techniques may be used for surgical training during the early learning curve of junior residents in general surgery. However, further large and prospective studies are warranted to confirm our findings.

\section{References}

1. Gearhart SL, Wang MH, Gilson MM, Chen B, Kern DE. Teaching and assessing technical proficiency in surgical subspecialty fellowships. J Surg Educ. 2012; 69(4): 521-8.

2. Kirton OC, Reilly P, Staff I, Burns K. Development and implementation of an interactive, objective, and simulation-based curriculum for general surgery residents. J Surg Educ. 2012; 69(6): 718-23.

3. Ruesch S, Walder B, Tramèr MR. Complications of central venous catheters: internal jugular versus subclavian access--a systematic review. Crit Care Med. 2002; 30(2): 454-60.

4. Plumhans C, Mahnken AH, Ocklenburg C, Keil S, Behrendt FF, Günther RW, et al. Jugular versus subclavian totally implantable access ports: catheter position, complications and intrainterventional pain perception. Eur J Radiol. 2011; 79(3): 338-42. doi: 10.1016/j. ejrad.2009.12.010.

5. Seldinger SI. Catheter replacement of the needle in percutaneous arteriography; a new technique.Actaradiol. 1953; 39(5): 368-76.

6. Gibson TJ. Subclavian Vein Catheterization. Operative Techniques in General Surgery. 2001; 3(4): 203-16. doi:10.1053/otgn.2001.27728.

7. Cambria R. Cannulation of the Internal Jugular Vein. Operative Techniques in General Surgery.2001; 3(4): 217-25. doi:10.1053/ otgn.2001.27733.

8. Batista TP, Sabat BD, Melo PS, Miranda LE, Fonseca-Neto OC, Amorim AG, et al. Impact of MELD allocation policy on survival outcomes after liver transplantation: a single-center study in northeast Brazil. Clinics (Sao Paulo). 2011; 66(1): 57-64.

9. Batista TP, Sabat BD, Melo PS, Miranda LE, Fonseca-Neto OC, Amorim $\mathrm{AG}$, et al. Employment of MELD score for the prediction of survival after liver transplantation. Rev Col Bras Cir. 2012; 39(2): 105-11.

10. Ferreira EA, Rasslan S. Surgical Education in Brazil. World J Surg. 2010; 34(5): 880-3.

11. Batista TP, Reis TC, Lucena MA, Ehrhardt RA, Araújo RG, Brandão PM.
Impact of Medical Residency on Surgical Oncology Care at a Brazilian University Hospital. Rev Bras Cancer. 2011; 57(2): 217-22.

12. National Committee of Medical Residency (CNRM): MEC. Resolution CNRM/MEC 02/2006 [Brazilian National Ministry of Education web site]. Cited on: March 4, 2014. Available from: http://portal.mec.gov. br/dmdocuments/resolucao02_2006.pdf.

13. Ma IW, Teteris E, Roberts JM, Bacchus M. Who is teaching and supervising our junior residents' central venous catheterizations? BMC Med Educ. 2011; 11: 16.

14. Ishizuka M, Nagata H, Takagi K, Kubota K. Right internal jugular vein is recommended for central venous catheterization. J Invest Surg. 2010; 23(2): 110-4. doi: 10.3109/08941930903469342.

15. Biffi R, Orsi F, Pozzi S, Pace U, Bonomo G, Monfardini L, et al. Best choice of central venous insertion site for the prevention of catheterrelated complications in adult patients who need cancer therapy: a randomized trial. Ann Oncol. 2009; 20(5): 935-40.

16. Dexheimer-Neto FL, Roehrig C, Morandi P, Oliveira RP, Teixeira C, Maccari JG, et al. Safety of a training program for ultrasoundguided internal jugular vein catheterization in critically ill patients. RevAssocMed Bras. 2011; 57(4): 394-7.

17. de Oliveira EB, Reis MA, Avelar TM, Vieira SC. Totally implantable central venous catheters for chemotherapy: experience with 793 patients. RevColBras Cir. 2013; 40(3): 186-90.

18. Miranda RB, Lopes JRA, Cavalcante RN, Kafejian O. Perviedade e complicações no seguimento de cateteres venosos totalmente implantáveis para quimioterapia. J Vasc Bras. 2008; 7(4): 316-20. DOI: $10.1590 /$ S1677-54492008000400005.

19. Bruzoni M, Slater BJ, Wall J, St Peter SD, Dutta S. A prospective randomized trial of ultrasound- vs landmark-guided central venous access in the pediatric population. J Am Coll Surg. 2013; 216(5): 939 43.

20.Turker G, Kaya FN, Gurbet A, Aksu H, Erdogan C, Atlas A. Internal jugular vein cannulation: an ultrasound-guided technique versus a landmark-guided technique. Clinics (Sao Paulo). 2009; 64(10): 98992. Clinics (Sao Paulo). 2009 Oct; 64(10): 989-992. doi: 10.1590/ S1807-59322009001000009.

21. Flato UP, Petisco GM, Santos FB. Punção venosa guiada por ultra-som em unidade de terapia intensiva. Rev Bras TerIntensiva. 2009; 21(2): 190-6. DOI: 10.1590/S0103-507X2009000200012. 